\title{
(Mis)Understanding scientific disagreement: Success versus pursuit-worthiness in theory choice
}

\author{
Eli I. Lichtenstein
}

\begin{abstract}
Scientists often diverge widely when choosing between research programs. This can seem to be rooted in disagreements about which of several theories, competing to address shared questions or phenomena, is currently the most epistemically or explanatorily valuable-i.e. most successful. But many such cases are actually more directly rooted in differing judgments of pursuit-worthiness, concerning which theory will be best down the line, or which addresses the most significant data or questions. Using case studies from $16^{\text {th }}$-century astronomy and $20^{\text {th }}$-century geology and biology, I argue that divergent theory choice is thus often driven by considerations of scientific process, even where direct epistemic or explanatory evaluation of its final products appears more relevant. Broadly following Kuhn's analysis of theoretical virtues, I suggest that widely shared criteria for pursuitworthiness function as imprecise, mutually-conflicting values. However, even Kuhn and others sensitive to pragmatic dimensions of theory 'acceptance', including the virtue of fruitfulness, still commonly understate the role of pursuit-worthiness - especially by exaggerating the impact of more present-oriented virtues, or failing to stress how 'competing' theories excel at addressing different questions or data. This framework clarifies the nature of the choice and competition involved in theory choice, and the role of alternative theoretical virtues.
\end{abstract}

Keywords: Theory choice; pursuit-worthiness; theoretical virtue; research problem selection; scientific disagreement; methodology

\section{Introduction}

Confronted with competing theories or research programs, even the best scientists often part ways. The major sources of this common divergence in theory choice can be unclear, though - in part because intuitive notions of 'theory choice' can obscure several ambiguities. Central among these are distinct views concerning what it means for scientists to 'choose' one or another competing theory, and what it means for theories to 'compete' with each other, in the first place. Thus, for instance, it is famously contested whether choosing or accepting a theory involves believing that it is (approximately) true, as scientific realists might propose; or whether, as some anti-realists suggest, acceptance

\footnotetext{
$\uparrow$ Version of record = Lichtenstein, E. I. (2021). (Mis)Understanding Scientific Disagreement: Success versus pursuit-worthiness in theory choice. Studies in History and Philosophy of Science Part A, 85, 166-175. DOI: 10.1016/j.shpsa.2020.10.005 + Contact: Eli I. Lichtenstein, University of Michigan; elicht@umich.edu
} 
is a less narrowly epistemic attitude that involves commitment to use or develop a theory, without necessarily believing it to be true (e.g. van Fraassen, 1980, 2007; Bueno, 1999). ${ }^{1}$ Likewise, although less frequently discussed, it is unclear whether theories genuinely compete only when they yield mutually inconsistent claims, as in Copernican and Ptolemaic astronomers debating whether the Earth orbits the Sun, rather than vice versa; or whether theoretical 'competition' also encompasses more indirect forms of rivalry for resources.

In this light, I will argue below, using case studies from early modern astronomy and $20^{\text {th }}$-century geology and biology, that one apparently strong explanation for divergent theory choice is often, in fact, extremely misleading. Namely, many cases in which scientists choose different research programs appear to be rooted in disagreements about which of several rival theories, competing to address shared questions or phenomena, is currently the most epistemically or explanatorily valuable. But many such cases are really more so rooted in divergent assessments of which theory will be best down the line, or which addresses the most significant data or questions. In other words, what appear to be disputes about which theory is most successful, given its current explanatory or epistemic value, are often in fact more so disputes about which is most pursuit-worthy. Earlier commentators have offered valuable accounts of pursuitworthiness (e.g. Laudan, 1977; Whitt, 1990; Achinstein, 1993; Šešelja and Straßer, 2013; Nyrup, 2015, 2019), but without thus arguing that apparent disputes about success often more directly concern pursuit-worthiness.

I draw several interrelated conclusions from this descriptive thesis about the sources of systematic divergence in scientific theory choice. First, certain common conceptions of theory choice or attitudes like acceptance have unexpectedly limited purchase on scientific practice. This includes both narrowly epistemic accounts and some pragmatically-inflected accounts offered by anti-realists. Insofar as many anti-realists do emphasize the relation between theory choice or acceptance and practical commitment to a given theory's ongoing development, my analysis indirectly illustrates the explanatory power of notions of acceptance or theory choice similar to those advocated by many antirealists. But anti-realist notions of acceptance or theory choice still often encompass both a theory's current value (including its current usefulness) and its prospective value. ${ }^{2}$ Hence, I also show that such broad appeals to pragmatic dimensions of theory choice have less explanatory purchase on scientific practice than some anti-realists might hope. I do not aim to supplant existing concepts of pragmatic 'acceptance', but the notion of

\footnotetext{
${ }^{1}$ Anti-realists who are skeptical of analyzing realism in terms of 'acceptance', like Rowbottom (2019), can still address theory choice by claiming that some theoretical virtues are "purely pragmatic" (Rowbottom, 2010, p. 247).

${ }^{2}$ E.g. compare van Fraassen (1980)-I elaborate this example below, in section 2.
} 
pursuit-worthiness that I stress more directly illuminates certain important dynamics of divergence in theory choice.

Second, however, my argument does not just concern the distinction between a theory's present and future value. Appraisals of pursuit-worthiness also encompass considerations of problem salience and methodological approach, that is, researchers' assessments of which questions or data are most significant, and of how to best approach them. ${ }^{3}$ This relates to the second kind of ambiguity mentioned above, about what it means for theories to be 'competing'. At the extreme limit, someone who aimed to 'choose' between theories in totally disparate fields of inquiry, like quantum mechanics and the Darwinian theory of evolution by natural selection, could rightly be accused of making a basic mistake. These two theories simply are not competing, in the relevant sense, and it therefore makes little sense to 'choose' between them. Intuitively, then, theories can truly compete only if they are about the same thing. But the case studies I develop below indicate that reality is less clear-cut than this intuitive gloss suggests. Competing research programs that are 'about the same thing' at coarse-grained levels of description still typically emphasize different finer-grained questions, data, or methods. Scientists thus often 'choose' more passively between competing theories, simply by stressing different questions, data, or methods. The result is a kind of practical divergence, driven largely by incompletely-overlapping research priorities.

Third, I suggest that widely shared criteria for pursuit-worthiness function as imprecise, mutually-conflicting values or heuristics. This broadly aligns with Kuhn's analysis of theoretical virtues like simplicity or empirical fit as "values" amenable to variable interpretation and application, rather than "rules" that dictate singular choices (Kuhn, 1977; see also Kuhn, 1970, pp. 152-154). Notably, Kuhn uses this contrast between values and rules to frame an influential explanation of rational disagreement in theory choice. ${ }^{4}$ His thought is that the inherent imprecision of values - compounded by tension between different values and the ambiguity of their relative weighting (Kuhn, 1977, pp. 322-324) - allows scientists to disagree about a given theory's merits, even while sharing the same basic standards for theoretical appraisal. Shared virtues only hold anything close to universal appeal if they remain vague or resistant to clear-cut

\footnotetext{
${ }^{3}$ On which situations stand most in need of explanation, epistemically speaking, see Grimm (2008); Laudan (1977, pp. 14-15); Bromberger (1992, ch. 1, 5). On the role of sociopolitical or non-epistemic values in problem choice, vis-à-vis theory appraisal, see Longino (1990); Elliott and McKaughan (2009) (cf. Dorato, 2004); Douglas (2009).

${ }^{4}$ Hempel (1983, p. 97, note 41) points to several others before Kuhn who stressed the "imprecision" of theoretical desiderata: Kries (1886, p. 26, pp. 29ff); Nagel (1939, pp. 68-71); and Carnap (1950, pp. 219 233). But Kuhn has arguably had more impact on recent accounts of theory choice and theoretical virtue. Dellsén and Baghramian (2020) thus call Kuhn (1977) "influential" and even "famous[]" vis-à-vis analysis of rational disagreement; see also Seidel (2019). The influence of Kuhn (1977) is apparent, e.g., in McMullin (1982, 1993); Laudan (1984, 2004); Longino (1995, 1996); and Schindler (2018).
} 
application; hence, valuing 'simplicity' in theories is like valuing 'freedom' in politics. Kuhn's framework thus lends simultaneous credence to two intuitive but superficially incompatible notions: that there is fairly broad consensus about what makes for a good scientific theory, but that scientific dissensus is still often rational (if not even beneficial). ${ }^{5}$ Hence, I aim in part to elaborate a basic Kuhnian model, by isolating a revealing trend in the balance of virtues that underlies divergence in theory choice. What appears to be disagreement concerning virtues like simplicity or empirical fit - and Kuhn's analysis can easily reinforce this impression - often more directly concerns virtues like prospective fruitfulness. ${ }^{6}$ This addresses an important lacuna, if not a serious limitation, in Kuhn's account.

Fourth, and finally, my analysis clarifies the role of alternative theoretical virtues, like the "feminist virtues" that Longino $(1995,1996,1997)$ proposes in response to Kuhn. I suggest that virtues like Longino's ontological heterogeneity and complexity of relationship, which she argues stand in tension with standard virtues like simplicity, are often productively understood as guiding researchers towards certain questions and phenomena, rather than as domain-neutral epistemic or explanatory desiderata. Alternative virtues can act as criteria for pursuit-worthiness, then, even if traditional virtues like simplicity mark explanatory success.

The plan of the paper is as follows. In section 2, I distinguish several common concepts of acceptability, adequacy, and pursuit-worthiness, to clarify my own notions of pursuit-worthiness and success. In section 3, I elaborate Kuhn's basic model of rational disagreement arising from differing interpretations or weightings of shared values, arguing that future-oriented virtues like fruitfulness figure more centrally than he seems to suggest. In section 4, I use a case study from geology to show how problem salience and methodological approach also bear on pursuit-worthiness. In section 5, I relate this to the status of alternative theoretical virtues in Barbara McClintock's work on maize genetics. Section 6 then provides a brief summary and conclusion.

\section{Acceptance, Success, and Pursuit-Worthiness}

Before turning to analyze concrete cases of divergent theory choice, a brief discussion of terms like 'pursuit-worthiness', 'adequacy', and 'acceptance' is first in order. Disambiguating several common senses of each will help to clarify my notions of pursuit-worthiness and success.

\footnotetext{
${ }^{5}$ Kuhn (1977, p. 332) argues that disagreement yields the simultaneous pursuit of incompatible theories, which acts as a form of communal bet-hedging. Compare Hull (1988, p. 521); Kitcher (1990); Kelp and Douven (2012).

${ }^{6}$ Kuhn's 'fruitfulness' is the closest of his virtues to my 'pursuit-worthiness' - see section 2 for elaboration.
} 
For some commentators, appraisal of a theory's 'adequacy' or 'acceptability' includes assessment both of its current epistemic or explanatory value and of its prospective value or suitability for ongoing development. Kuhn, for instance, describes all of the basic desiderata he identifies - accuracy, consistency, broad scope, simplicity, and fruitfulness - as "criteria for evaluating the adequacy of a theory" (Kuhn, 1977, p. 322). A theory is fruitful, on Kuhn's view, insofar as it has a capacity to "disclose new phenomena or previously unnoted relationships among those already known" (Kuhn, 1977, p. 322). This broad definition leaves it unclear whether he means to indicate a demonstrated capacity to 'disclose new phenomena or previously unnoted relationships' or rather a prospective capacity of this sort. But his elaboration that scientists are "especially attracted by a theory that promises the concrete successes for which [they] are ordinarily rewarded" (Kuhn, 1977, p. 322, note 6) suggests that he means to highlight at least the latter future-oriented capacity, if not also the former demonstrated capacity. ${ }^{7}$ Thus appraisals of adequacy, in Kuhn's sense, evidently encompass appraisals of both a given theory's current epistemic or explanatory value and its more prospective (and more pragmatic) value for research.

For others commentators, however, the virtue of 'fruitfulness' or 'fertility' more centrally indicates a demonstrated capacity. In this vein, for example, McMullin (1976, p. 400) distinguishes between a theory's ("proven") ' $P$-fertility', or "actual success[...]in opening up new areas, in meeting anomalies, and so forth," and its ' $U$-fertility' or "asyet-untested promise" - i.e. its "potential" for "further (as yet untested) development." In turn, and further unlike Kuhn, McMullin (1976, p. 400) argues that $P$-fertility (but not $U$ fertility) "confirms the truth-value of a theory." (Kuhn does not view traits like simplicity, let alone fruitfulness, as marks of a theory's truth. He could still allow that traits like simplicity have explanatory value, however, or that they tend to promote the broadly epistemic goal of empirical adequacy. ${ }^{8}$ ) I will here remain agnostic on the question of whether pursuit-worthiness, in my sense, has epistemic or explanatory value - although in subsequent sections I will elaborate on how appraisals of current success might be taken to bear on appraisals of pursuit-worthiness. This interaction does not undermine my claim that apparent disagreements about success are often more directly about pursuit-worthiness: even granting that success can bear on pursuit-worthiness, assessing a theory's pursuit-worthiness is still a conceptually and practically distinct task from assessing its present success.

\footnotetext{
${ }^{7}$ Note that past fertility may sometimes be evidence for ongoing fertility.

${ }^{8}$ Some argue that the history of science grounds legitimate inductive arguments to the effect that deference to traditional superempirical theoretical virtues has reliably resulted in the development of (increasingly) empirically adequate theories, and hence plausibly will continue to do so. This has been suggested by both anti-realists (compare Kuhn, 1977, p. 335) and realists (e.g. McMullin, 1982, p. 21). See also Quine and Ulian, 1970, p. 47.
} 
Van Fraassen will serve as a final example of someone who adopts a broad notion of 'acceptance', including aspects of both success and pursuit-worthiness, in my sense. In the anti-realist sense that van Fraassen embraces, 'accepting' a given theory involves both belief that this theory is empirically adequate and a more practical "commitment" to "confront any future phenomena by means of the conceptual resources of this theory" (van Fraassen, 1980, p. 12). This is closely related to his views about the status of theoretical virtues beyond empirical adequacy or strength, like simplicity: these superempirical virtues are "pragmatic virtues," on van Fraassen's view, which "do not concern the relation between the theory and the world, but rather the use and usefulness of the theory" (van Fraassen, 1980, p. 88); they are thus "a function of our pleasures and interests" (van Fraassen, 1980, p. 87). In this light, he moreover links super-empirical virtues to the "pragmatic aspect" of explanation: virtues like simplicity contribute to a "purely pragmatic" dimension of "explanatory power" (van Fraassen, 1980, pp. 88-89). It is a significant limitation of van Fraassen's framework, however, that he combines considerations of current pragmatic utility or explanatory power with a forward-looking commitment to 'confront' phenomena with the resources of a given theory. The latter can evidently include both a commitment to use a theory (e.g. to explain) and a commitment to develop it. But these distinct commitments can come apart in important ways. In particular, van Fraassen's broad notions of 'acceptance' and 'pragmatic' dimensions of theory choice threaten to obscure the dynamic that is my focus: many cases of divergent theory choice which are apparently rooted in disagreements about certain theories' current epistemic or explanatory value - whether or not explanation has a 'pragmatic aspect' - are really more directly rooted in divergent appraisals of pursuit-worthiness. The same basic objection also applies to Kuhn's broad notion of 'adequacy'. This is not to suggest that either Kuhn's or van Fraassen's categories should be abandoned, let alone replaced with my own. It is just to maintain that my approach has certain notable explanatory benefits.

Of course, other commentators do distinguish 'pursuit-worthiness' from 'adequacy' or 'acceptability', in a way that is closer to my framework. Laudan, for example, defines adequacy in terms of demonstrated effectiveness in problem-solving (Laudan, 1977, p. 106), before distinguishing appraisals of "(momentary) adequacy" or acceptability from appraisals of pursuit-worthiness - although he takes both to be core elements of scientific rationality (Laudan, 1977, pp. 108-120). In turn, for Laudan, the pursuit-worthiness of a given "research tradition" is rooted in its degree of "progressiveness," or how its 'momentary adequacy' has increased or decreased over time (Laudan, 1977, p. 107). Given his broadly Kuhnian appeal to 'problem-solving', Laudan hence claims that pursuit-worthiness is to be judged in terms of comparative rates 
of problem solution. Research traditions can thus be acceptable without being pursuitworthy, and vice versa (Laudan, 1977, pp. 106-119).

The crucial point about Laudan's distinction, for my purposes, is that pursuitworthiness can differ from adequacy (or acceptability or success) even if adequacy (or acceptability or success) is defined in terms of demonstrated effectiveness in problemsolving, rather than in terms of truth or epistemic justifiability, more narrowly construed. Three further points also warrant brief mention. First, my analysis below does not require that Laudan's account of pursuit-worthiness is correct. Indeed, the case studies I present suggest that comparative rate of problem-solution is only one among many relevant determinants of scientific pursuit-worthiness. Second, my discussion does not require that Laudan's account of 'adequacy', in terms of effective problem-solving, is the best option. In fact, I favor a somewhat more traditional view, according to which a theory's success is a matter of how well it currently realizes basic explanatory or epistemic goals. (I use 'success' instead of standard terms like 'adequacy' or 'acceptability' to prevent misleading conflations of my framework with more common ones.) Note that this characterization of success leaves it open whether explanatory goals like simplicity have any epistemic value. And it also leaves it open whether the epistemic goals in question include literal truth or accuracy in describing unobservable things, as in scientific realism, or rather just the aim of empirical adequacy, as in constructive empiricism or other antirealisms. Finally, whether one chooses to distinguish success from current 'acceptability' may depend on how one takes acceptability to be related to epistemic goals like truth or knowledge. For example, Elgin defines 'acceptance' of $p$ in terms of "being willing to take $p$ as a premise, as a basis for action or[...] as an epistemic norm or a rule of inference, when one's ends are cognitive" (Elgin, 2017, p. 19; compare Cohen, 1992). Thus construed, Elgin's (or van Fraassen's) 'acceptability' is in some ways closer to my 'pursuit-worthiness' than to Laudan's 'adequacy'-let alone to more veritistic ideals of 'acceptability', according to which truth is necessary for acceptability (Adler, 2002; compare Goldman, 1999).

For my purposes, a theory's success can be understood as how well it currently realizes basic explanatory or epistemic desiderata. By contrast, judgments of pursuitworthiness are just that: judgments of how (scientifically) worthy of pursuit or ongoing development a given theory is. Judgments of pursuit-worthiness therefore include prospective or forward-looking judgments of a theory's future success-e.g. its future simplicity and empirical fit, given one's commitment to develop it. But another (related) thing that can make a research program worthy of pursuit is that it involves a good methodological approach to problems. For example, injunctions to 'Simplify' or to 'Focus on data that violate expected patterns' can give a scientist something worthwhile to do going forwards, whereas already-achieved explanatory or epistemic success does 
not, in itself. Finally, a research program can be more worthy of pursuit because it focuses on significant questions or data, at least when it has not yet addressed them fully successfully. A research program which promises to raise and successfully solve many new but uninteresting problems is intuitively less worthy of pursuit than it would be if it had a more important focus. And a research program which poses good questions is thereby more worthy of pursuit, even though one can pose a good question without having succeeded at all in responding to it. One might object that problem salience and methodological approach are not directly related to pursuit-worthiness - especially if one intuitively links 'pursuit-worthiness' just to prospective judgments of success. But note that one need not conflate issues of problem salience or methodological approach with the issue of which theory will be most successful in order to appreciate that both bear directly on the question of which theories are more worthy of pursuit.

Still, research problem salience and methodological approach may seem to be too closely related to success, in a way that undermines my distinction between success and pursuit-worthiness. For example, it might seem that one can argue that a given theory is right now more successful than another theory on the grounds that it addresses more significant data or questions. However, this is far from clearly true. If only solutions to research problems can be the bearers of explanatory or epistemic (dis)value, for example, then it would not be true that focus on good problems alone-i.e. absent good solutions to those problems - can contribute directly to explanatory or epistemic value. Moreover, even if one allows that problems or explananda themselves can have epistemic or explanatory value, one could still draw a distinction between (1) the epistemic or explanatory value of research problems and (2) the epistemic or explanatory value of research problem solutions (or theories, models, explanations, etc.). In the sense relevant to my argument, 'success' is a matter of the current epistemic or explanatory value of research problem solutions, theories, models, explanations, etc.-i.e. 'success' is directly related to (2), and not to (1). Likewise, a methodological heuristic like 'Pay attention to data that violate expected patterns' may have only instrumental epistemic or explanatory value-for example, by reliably promoting the development of theories, models, or explanations that have final epistemic or explanatory value. In this light, one could associate 'success' with final rather than instrumental epistemic or explanatory value. Regardless, 'success' in my sense is a matter of the epistemic or explanatory value of products of inquiry like theories, models, explanations, or problem solutions-not a matter of any direct epistemic or explanatory value that research problems or methods themselves may have.

Good assessments of pursuit-worthiness may thus require making informed estimates of a given theory's future developmental trajectory, given one's practical commitment to developing it, as either an individual scientist or a member of a broader 
research community. But good assessments of pursuit-worthiness may also require making informed judgments about which research problems or phenomena are most worth addressing or explaining. Thus my basic empirical claim is that cases of divergent theory choice that seem to involve disagreements about rival theories' current explanatory or epistemic value - including demonstrated success in 'problem-solving'are often, in fact, driven more directly by scientists' diverging appraisals of which theory will be best, later on, or which addresses the most important data or questions. ${ }^{9}$

\section{Kuhn's Model and Its Limits in the Copernican Case}

With these points of terminology and context in tow, we may now turn to case studies. Here it will prove helpful to begin by considering one of Kuhn's examples: $16^{\text {th }}$ century astronomers faced a choice between Ptolemaic geocentric theories and heliocentric approaches building upon Copernicus's work.

Kuhn hopes to explain divergent choice between Ptolemaic and Copernican systems by appeal to differing interpretations or weightings of shared 'values'. For instance, astronomers who valued simplicity might have been impressed by the fact that Copernican models allowed for the explanation of certain qualitative features of planetary trajectories, including retrograde motion and the continual proximity of the inferior planets (Mercury and Venus) to the Sun in the sky, without recourse to epicycles, eccentrics, and equants (Kuhn, 1977, p. 324). But others who interpreted simplicity differently could just as easily have seen this conceptual parsimony as illusory, given that epicycles and eccentrics had to be reintroduced to Copernican theory in order for it to achieve quantitative predictive accuracy comparable to that of sophisticated geocentric models (Kuhn, 1957, pp. 167-172). Variable interpretation of shared desiderata aside, Copernican and Ptolemaic theories arguably each displayed certain desiderata more strongly than did the other. For example, the Copernican system was inconsistent with many then-widely-accepted physical theories, largely of Aristotelian origin, that made crucial reference to a stationary central earth. The latter provided explanations of "how stones fall, how water pumps function, and why the clouds move slowly across the sky," among other things. Hence, Kuhn concludes, "the consistency criterion, by itself[...] unequivocally for the geocentric tradition" (Kuhn, 1977, p. 323).

Notably, though, diversity in interpretation or relative weighting of shared explanatory or epistemic desiderata fails to accommodate all, and even some of the most important, intra-disciplinary factors contributing to divergent theory choice among $16^{\text {th }}$ century astronomers. In his Preface to De Revolutionibus, Copernicus argues that the

\footnotetext{
${ }^{9}$ My framework has broader explanatory scope insofar as my notion of success is consistent with both realist and anti-realist views of the epistemic status or goals of science. This approach is compatible with further distinguishing realist and anti-realist forms of 'success'; but the conclusions I aim to establish do not require use of this distinction.
} 
once-admirable elegance of the geocentric framework had been gradually destroyed by the introduction of new conceptual machinery (like epicycles, eccentrics, and equants), in pursuit of predictive accuracy. ${ }^{10}$ Consequently, it appeared to Copernicus that Ptolemaic systems could be simple o rempirically adequate, but not both simultaneously (Copernicus, 1957 [1543], p. 507). Superficially, this seems to be entirely in keeping with Kuhn's analysis: perhaps Copernicus's atypical rejection of the Ptolemaic tradition was the result of the particular nexus of explanatory desiderata, interpreted idiosyncratically, that he brought to bear in evaluating Ptolemaic theories. ${ }^{11}$ But this basic interpretation demands refinement, since at the time Copernicus began his investigation of heliocentrism - hence, prior to his own development of a comprehensive alternative framework - there was evidently no astronomical system that Copernicus himself would have judged to be more successful than the Ptolemaic system, or perhaps even comparable to it. Copernicus's negative review of Ptolemaic astronomy would not have actually resulted in divergent 'theory choice' unless it also incorporated an essentially methodological critique, with two parts: first, his judgment that Ptolemaic systems were unlikely to become both simpler and more accurate via continued internal revision; second, his further judgment that he might be able to do better by means of a more fundamental conceptual reorientation. In the absence of these supplementary procedural judgments, it is implausible to suppose that Copernicus would have initially departed from Ptolemaic geocentrism, even given his substantial explanatory qualms with that tradition.

Perhaps this appears to be a rather pedantic point, which has no bearing on $16^{\text {th }}$ century astronomical theory choice beyond that of Copernicus himself. After all, one might think that after the publication of De Revolutionibus in 1543, astronomers had a concrete Copernican system to measure against traditional Ptolemaic systems, so that theory choice could then be governed by evaluations of comparative explanatory merit. This is at best misleading, however, insofar as it suggests that scientific theory choice is a process of selection between completed frameworks. In fact, of course, scientists are concerned to continually develop theories, with the result that judgments of pursuitworthiness can continue to diverge from judgments of success. Explanatory desiderata thus function prominently in scientific decision-making as motivation for corresponding methodological heuristics: commitment to the explanatory value of quantitative accuracy drives scientists to attempt to increase theories' quantitative accuracy, and can do so even with respect to a theory that is currently less accurate than salient rivals; deference to

\footnotetext{
${ }^{10}$ Copernicus was especially troubled by the use of equants—see Book 4, Section 2 of De Revolutionibus.

${ }^{11}$ E.g. see Kuhn (1957, pp. 128-132) for a discussion of Neoplatonism's impact on Copernicus's ideal of simplicity.
} 
consistency leads scientists to resolve outstanding inconsistencies; and so on for other desiderata.

Indeed, divergence in the interpretation and weighting of such methodological heuristics was a significant driver of dissensus in the $16^{\text {th }}$-century astronomical community, whereas there was in fact a fair amount of agreement regarding the explanatorily satisfying (and problematic) aspects of Copernican theory. For instance, many astronomers appreciated Copernicus's techniques for eliminating equants, but not all who did so embraced his heliocentrism. Rather, numerous astronomers-including Tycho Brahe (Blair, 1990, p. 256) and mid-16 ${ }^{\text {th }}$-century researchers at Wittenberg (Westman, 1975, p. 167) — consciously attempted to transfer Copernicus's equantless computational techniques to geocentric systems, precisely because they shared his conception of the explanatory value of mathematical harmony and regularity, and his view that the use of equants violated this standard. In this context, therefore, Copernicans and their critics differed most widely in their methodological responses to a shared judgment regarding the explanatory merit of Copernicus's equantless techniques, leading most researchers to attempt to incorporate some Copernican methods into their preferred astronomical schema. Similarly, the French astronomer Jean-Baptiste Morin later introduced Keplerian ellipses into a geocentric reference frame (Westman, 1994, p. 106) - again, the point being that Morin could judge elliptical orbits to be a promising means of increasing simplicity (and accuracy) without accepting all other aspects of the research program in which they were originally proposed. Thus it is not at all clear, contra Kuhn, that the astronomers most impressed by the simplicity of Copernicus's approach were ipso facto any likelier to accept his basic heliocentric theory. Rather, these astronomers were simply the most likely to try to incorporate aspects of Copernican method into their own research programs. Only those who made a further judgment, to the effect that the simplicity of Copernicus's approach required heliocentrism, would have taken the simplicity of his approach to be a clear argument in favor of heliocentrism. But as the above details indicate, the extent of the interdependence between Copernicus's heliocentrism and the mathematical harmony of his approach was in fact an open research question for $16^{\text {th }}$-century astronomers.

In addition to widespread agreement regarding the admirable simplicity of certain aspects of the Copernican approach, astronomers generally felt that the incompatibility of Copernicus's system with Aristotelian physical theory was problematic. Not all astronomers responded in the same way to this problem of inconsistency, though. Again, some tried to resolve it by transferring (what they felt to be) the laudable aspects of Copernican methodology to geocentric systems. But others, like Copernicus himself, began discussing non-geocentric alternatives to Aristotelian physics. In Book I of De Revolutionibus, for example, he suggests that "gravity or heaviness is nothing except a 
certain natural appetency implanted in the parts by the divine providence of the universal Artisan, in order that they should unite with one another in their oneness and wholeness and come together in the form of a globe" (Copernicus, 1957 [1543], p. 521). This is in contrast to the Aristotelian notion that heavy objects fall towards the center of the universe. Kepler in turn elaborated a related view of gravity as the attraction of terrestrial matter towards the center of the earth. And other post-Copernican researchers, like Giordano Bruno and Galileo, worked to develop dynamical theories (based on the concept of impetus and the law of inertial motion, respectively) that were consistent with the notion of a moving Earth-evidently inspired in part by Copernicus's cosmological vision (Koyré, 1943; Naylor, 2003). Scientists could thus recognize the inconsistency of Copernican astronomy with received physical theory, and even judge this inconsistency to be acutely problematic for Copernicus's program, while nevertheless deciding to work within either a heliocentric or a geocentric framework. Indeed, the advancement of nongeocentric physics was crucial to the ongoing development of heliocentric astronomical theory. The inconsistency of Copernicus's system with Aristotelian physics may have constituted an explanatory flaw in the view of many $16^{\text {th }}$-century astronomers. But this inconsistency was also a problem to be solved by the contemporary scientific community - and so even an opportunity for progress.

Scientists can thus be attracted to a theory precisely by virtue of its explanatory weaknesses. Of course, scientists do not pursue theories that they judge to have no explanatory or epistemic value. But specific explanatory weaknesses within otherwise promising approaches signal concrete directions for future research. Kuhn's basic model is compatible with this point, but his broad notion of 'adequacy' (which effectively combines success and pursuit-worthiness) can obscure it. From this perspective, it may indeed be true that, for instance, "the consistency criterion spoke unequivocally for the geocentric tradition," as Kuhn (1977, p. 323) claims. But from a more methodological perspective, the inconsistency of Copernican astronomy with received physical theory constituted an interesting research problem that could be, and was, approached in various ways by different researchers.

Aspects of the above discussion generalize readily to the class of theoretical upheavals in the history of science preceded by states of internal 'crisis'. Both Kuhn (1970) and Laudan (1977) argue that at least some cases of rapid scientific development are foreshadowed by periods during which increasingly many scientists become dissatisfied with dominant theoretical approaches due to their inability to sustain routine forms of scientific 'puzzle-solving'. In such cases, early converts to nascent scientific theories are often plausibly influenced more by atypical methodological judgments - to 
the effect that a dominant research program is stagnating, that a specific alternative theory or approach might be more successful in the long run, etc. - than by any notable idiosyncrasy in their explanatory standards.

Three objections to the above discussion warrant addressing. First, one might object that the above is all in fact consistent with Kuhn's model of 'value'-based disagreement. ${ }^{12}$ After all, am I not just pointing to the role played by fruitfulness? However, Kuhn's notion of fruitfulness is underspecified, for instance insofar as it remains ambiguous between a previously-demonstrated and a prospective capacity to "disclose new phenomena or previously unnoted relationships" (Kuhn, 1977, p. 322). And even if demonstrated fruitfulness adds to current explanatory or epistemic value, future promise alone need not. Moreover, Kuhn's invocation of virtues like simplicity and accuracy can be misleading in the Copernican case. He focuses on disagreement about virtues like simplicity or empirical fit even in a situation where divergent theory choice was evidently more directly rooted in forward-looking appraisals. My notions of success and pursuit-worthiness highlight this dynamic, whereas Kuhn's broad 'adequacy', which effectively mixes together considerations of success and pursuitworthiness, arguably tends to obscure it. Greater emphasis on pursuit-worthiness and less on direct appraisals of success is consistent with Kuhn's basic model of disagreement; but it is still a valuable refinement thereof.

A second objection is that even if, in a given case of theory choice, scientists agree about the importance of the different virtues marking explanatory or epistemic success, and agree about how well competing theories in their current form realize these 'success' virtues, there could still be substantial disagreement about whether certain theoretical claims are successful. Even if there was no fully developed heliocentric theory for Copernicus or his contemporaries to regard as 'more successful' than the Ptolemaic system, for example, there may still have been significant disagreement about whether to deem successful (or to 'accept', etc.) theoretical claims like 'Mars orbits around Earth'. Moreover, these kinds of disagreements about certain theoretical claims' success might have underpinned disagreements about pursuit-worthiness. For instance, those who judged the claim 'Mars orbits around Earth' to be better epistemically justified, or more explanatorily powerful, might have been likelier to find Ptolemaic systems more pursuitworthy.

This is all certainly true. Still, it is important to distinguish two claims: (i) divergent theory choice is often largely driven by assessments of pursuit-worthiness, which can rest in part on assessments of the success of certain theoretical claims (if not full theories); (ii) divergent theory choice is often largely driven by direct assessments of

\footnotetext{
${ }^{12}$ I am grateful to several anonymous reviewers for pressing me to clarify the relation between my notion of pursuit-worthiness and Kuhn's fruitfulness, as well as for raising the objections that conclude this section.
} 
the success of certain theoretical claims (or theories). I am here defending (i), at the expense of (ii). These are conceptually distinct claims, but they can also be intuitively distinguished in practice. If I am trying to figure out whether or not to pursue geocentric astronomy, then my degree of confidence that 'Earth is in the middle' should clearly play some role; but this confidence just is my sense of the degree to which the claim 'Earth is in the middle' epistemically succeeds. ${ }^{13}$ Even if appraisals of claims' success play a role in appraisals of theories' pursuit-worthiness, this does not entail that the latter are exhausted by or collapsible into the former. Nor does it undermine my claim that appraisals of pursuit-worthiness are often more directly relevant to divergent theory choice.

Third, one might object that even if the pursuit of nascent heliocentric systems was not predicated on their success, for Copernicus or his contemporaries, it could still have been rooted in their judgments that the Ptolemaic system had failed. But here it is crucial to avoid conflating two senses of 'failure': for a theory to be 'failed' can mean either that it is unsuccessful or that it is unable to continue (as in a failed business, which is no longer viable going forwards). Insofar as it is forward-looking, the latter sense of 'failure' is directly related to lack of pursuit-worthiness, not to lack of success. The former kind of failure-to-date can in turn provide evidence for such forward-looking failure or ongoing stagnation: the fact that a theory has not 'worked' so far can be a sign that it will not work even with further development. But it is the latter, prospective judgment of ongoing stagnation — not the distinct judgment of failure-to-date which may support it - that I claim is often more directly responsible for scientific theory choice.

\section{Problem Salience \& Methodological Approach in the Case of Sea-Floor Spreading}

Appraisals of pursuit-worthiness encompass not just direct assessments of a theory's future epistemic or explanatory value, but also those of problem salience and methodological approach - that is, judgments about which questions or data are most significant, and how to best approach them. Again, this relates to the question of what it means for theories to be 'competing'. Alternative research programs that are 'about the same thing' at coarse-grained levels of description, and so intuitively amenable to direct competition, nevertheless often emphasize different finer-grained questions, data, or methods. Scientists can thus 'choose' quite passively between theories that are engaged in de facto competition for attention and resources within a given field or subfield of inquiry, simply by stressing different questions, data, or methods. Real theory choice

\footnotetext{
${ }^{13}$ For an illuminating account of (dis)agreement in terms of degrees of belief, see Rowbottom (2018). E.g. note that Copernicans could have had atypically high confidence that 'the Sun is in the center' even without belief simpliciter.
} 
therefore commonly involves practical divergence driven by incompletely-overlapping research priorities.

Why address such incompletely-overlapping theories or research programs here, though, given that divergent 'choice' between them seemingly need not involve any real disagreement? ${ }^{14}$ This appearance is misleading, however. Here it is helpful to distinguish various kinds of real disagreement. Philosophical discussions of peer disagreement are commonly framed around questions like "whether $p$ when $\mathrm{A}$ and $\mathrm{B}$ are evidential and cognitive equals with respect to this question" (Lackey, 2013, p. 243), or scenarios in which "you and I have been exposed to the same evidence and arguments that bear on some proposition" yet nevertheless "arrive at different views about the question on the basis of our common evidence" (Kelly, 2013, p. 34). As Weinberger and Bradley have recently argued, though, it may be that scientific disagreements are "not, in general," like the cases of peer disagreement on which "philosophical discussions" thus "typically" focus: there are also "widespread" instances of what they call "non-factual disagreement," including those that largely "result" from "differences in the background methodological stances of those disagreeing," as opposed to disagreement about whether "some fact within the domain being investigated" is true (Weinberger and Bradley, 2020). ${ }^{15}$

In this light, note that there can be real disagreement about relative pursuitworthiness even in cases where the 'competing' theories in question were developed with attention to incompletely-overlapping sets of fine-grained research problems. As I acknowledged above, moreover, disagreements about the success or failure of certain theoretical claims (or 'factual' disagreements, etc.) do often bear on disagreements about pursuit-worthiness. Still, anyone aiming to apply the many recent philosophical discussions of peer disagreement to real cases of scientific theory choice should be cognizant that 'competing' research programs in fact commonly excel at addressing somewhat different questions or phenomena, especially when the problems organizing inquiry are subjected to appropriately fine-grained description.

Still, one might object that common philosophical accounts of disagreement are simply not meant to handle any and all cases of divergence in what scientists choose to work on. ${ }^{16}$ Hence, from the perspective of these common accounts of disagreement, 'incompletely-overlapping research priorities' may simply seem beside the point. Indeed, one might worry that it is almost analytically or trivially true that scientists take pursuitworthiness into account, when choosing what to work on. But these objections are not

\footnotetext{
${ }^{14} \mathrm{I}$ am grateful to two anonymous reviewers for raising this worry and pressing me to relate my discussion to recent epistemological treatments of (dis)agreement.

${ }^{15}$ Weinberger and Bradley do not discuss the kind of partial overlap in data or questions that I stress below.

${ }^{16} \mathrm{I}$ am grateful to an anonymous reviewer for raising the concerns to which I respond in the next two paragraphs.
} 
responsive to my basic empirical claim: what appear to be scientific disagreements about theories' current success, presumably including disagreements about 'whether $p$ ' for specific theoretical claims, are often in fact more directly - and more consequentiallyreal disagreements about pursuit-worthiness. That the latter sort of disagreement is not the focus of contemporary epistemological discussion does not undermine this point. In fact, it makes it more urgent: from the perspective of understanding the nature and sources of rational disagreement with consequential impact on actual scientific practice, the issue of rational disagreement about pursuit-worthiness is perhaps unexpectedly salient. An account of disagreement about pursuit-worthiness can thus have broader explanatory scope than one might have expected, whereas accounts of disagreement about theories' success or theoretical claims' likelihood have somewhat more restricted explanatory scope than one might expect. This does not mean that common philosophical accounts of disagreement are unimportant or have no valid application to scientific practice, or that these accounts explain less about science overall than does my approach. It just suggests that it is also a worthwhile project to develop a fuller analysis of disagreement about pursuit-worthiness. Common philosophical accounts of disagreement are not meant to handle cases of incompletely-overlapping research priorities, clearly. But since my aim is analyze rational disagreement underlying divergent theory choice, this difference in scope simply limits the utility of these common philosophical accounts.

It is trivially true that scientists take pursuit-worthiness into account when determining which theory to pursue. But it is not trivially true that scientists do not base their decisions about which theory to pursue as directly in appraisals of theories' or claims' current success as some philosophical frameworks can seem to suggest-as in Kuhn's specific appeals to present-oriented theoretical virtues in explaining the Copernican case, for example, if not also recent epistemological focus on disagreement about 'whether $p$ '. It is not trivially true that the causal impact of disagreements about 'whether $p$ ' can appear larger than it really is, within science, because alternative research programs that are 'about the same thing' at coarse-grained levels of description, and so intuitively amenable to direct disagreement about 'whether $p$ ', still often emphasize different finer-grained questions, data, or methods. Nor is it trivially true that real theory choice thus often involves divergence driven by incompletely-overlapping research priorities-reflecting genuine, even if only implicit, disagreements about pursuitworthiness - even in cases where direct appraisals of success might seem determinative.

The Copernican revolution hence represents a fairly atypical backdrop for theory choice to the extent that $16^{\text {th }}$-century Copernican and Ptolemaic astronomical systems were in fact designed with close attention to a truly shared set of specific problems - e.g. precise quantitative prediction of the observable motions of celestial bodies, and especially planets - and without major disagreement regarding the field of observational 
data to be accounted for (Kuhn, 1957). A more representative case, in the sense of more clearly illustrating that 'rival' research programs very often excel at addressing different fine-grained questions or data, is the ambivalence of geological scientists towards the theory of continental drift, before the early- to mid-1960s.

What proved to be crucial evidence in favor of drift theories was provided by the success of a model accounting for previously observed magnetic anomalies around midocean ridges, due to Vine and Matthews, and independently developed by Morley (Frankel, 1982). The Vine-Matthews-Morley (VMM) proposal synthesized the (at the time controversial) theory of sea-floor spreading ${ }^{17}$ with the notion of thermo-remanent magnetization in the oceanic crust ${ }^{18}$ and the (also controversial) hypothesis of periodic global magnetic pole reversals. This led to the inference that there should be alternating stripes of oppositely polarized magnetic materials in the oceanic crust extending outwards from mid-ocean ridges, with a central anomaly along the ridge axis magnetized in the current direction of the Earth's magnetic field (Vine and Matthews, 1963). The main theoretical rivals to the VMM hypothesis were immobilist models developed in the Lamont Geological Laboratory at Columbia, which assumed neither sea-floor spreading nor geomagnetic polarity reversals (Frankel, 1982). For example, Heirtzler and Le Pichon (1965) hypothesized that magnetic anomalies around mid-ocean ridges were the result of strongly magnetized materials upwelling through tensional fractures in the (nonspreading) oceanic crust.

Resistance to the VMM hypothesis within the Lamont research group seems to have been substantially motivated by its especially data-driven governing ethos (Frankel, 1982, pp. 34-38). Scientists from Lamont objected that the hypothesis of sea-floor spreading assumed in the VMM model was inconsistent with the observed age of sedimentary and basaltic samples collected near the axis of the Mid-Atlantic Ridge, many of which inconsistent data had in fact been collected by scientists at Lamont (e.g. Ewing et al., 1964). As in the case of Copernican astronomers' acknowledgment of the problematic inconsistency between heliocentrism and received dynamical theories, though, geologists could insist on the truth of sea-floor spreading even while recognizing the apparent inconsistency between this theory and the aforementioned data. Harry Hess, the originator of the sea-floor spreading hypothesis, simply concluded (as it turns out presciently) that some of these inconsistent data had been mislabeled or incorrectly dated

\footnotetext{
${ }^{17}$ Upwelling material from the Earth's mantle forms new oceanic crust along the axis of mid-ocean ridges. Ocean crust is thus youngest near mid-ocean ridges, and oldest at the ocean's edge (where it melts back into the mantle). This varying crustal age was not securely established empirically until 1970 (LeGrand, 1988, pp. 235-236).

${ }^{18}$ Certain rocks are permanently magnetized in the direction of the Earth's magnetic field at their time of formation.
} 
(Frankel, 1982, p. 36). ${ }^{19}$ And ultimately — but only after continental drift had already been universally accepted-geologists were forced to complicate the theory of sea-floor spreading in order to render it consistent with a small but steady stream of unexpectedlyaged sedimentary samples. ${ }^{20}$ This included positing sediment transfer across transform fault lines (Cifelli et al., 1968) and non-spreading pockets along ridge axes (Bonatti, 1973). The salient question for researchers studying oceanic magnetic anomalies, therefore, seems not to have been the evaluative question, Is it problematic that the VMM hypothesis as it stands is inconsistent with these data? Everyone might have readily agreed that this was a serious explanatory problem. Rather, dissensus seems to have emerged more directly from divergent responses to investigative questions like, Is it critical that a model of magnetic anomalies around mid-ocean ridges immediately account for these specific data, or should we aim to satisfactorily explain them only at some later time?

The Lamont group's data-driven attitude is best represented not simply as deference to empirical adequacy construed as a criterion for success, but moreover as deference to empirical adequacy construed as a correlative methodological prioritization of observational data collection and the explanatory accounting thereof, as opposed to more purely theory-driven modeling. Initial rejection of the VMM hypothesis seems to have been motivated at least partly by a procedural judgment to the effect that theorizing should start from a more comprehensive basis in specific oceanographic data of the sort that happened to present particular problems for the VMM model in its early stages of development. In other words, scientists at Lamont sought to develop an account of magnetic anomalies by something closer to direct 'induction' from certain oceanographic data, the immediate explanation of which they apparently prioritized more so than did early proponents of the VMM model. Lamont's approach thus spoke strongly against importing controversial hypotheses, like sea-floor spreading and geomagnetic polarity reversals, from disparate areas of geological science. And their empirical approach is most accurately construed as a methodological preference, rather than a narrowly explanatory or epistemic one.

This analysis is supported by retrospective commentary provided by James Heirtzler, one of the scientists at Lamont during the rise of drift theories:

We were people who were out there collecting data, and dealt only with theories that could be substantiated heavily with the facts-This is not to

\footnotetext{
${ }^{19} \mathrm{~A}$ basalt sample dredged from a ridge axis was radiometrically dated at $\sim 30$ million years old (Saito, Ewing, and Burckle, 1966), but this was later retracted and corrected to 3 million years upon retesting (Frankel, 1982, p. 36).

${ }^{20}$ E.g. Cifelli (1970); Melson et al. (1972).
} 
say that [theories of sea-floor spreading] were of no value. But we were data-oriented at Lamont.[...]They were rather esoteric subjects that did not seem to bear very heavily on our day to day work, certainly, before 1963 to 1965. (Frankel, 1982, p. 38)

It thus seems likely that scientists' divergent judgments regarding the pursuit-worthiness of the VMM hypothesis are explicable, in significant part, in terms of different research groups' prioritization of different data and different methodological approaches to their prioritized data.

This is not to deny that Lamont researchers disagreed with advocates of the VMM model about the success or plausibility of claims like 'Magnetic anomalies around midocean ridges are related to sea-floor spreading'. Nor is it to deny that these disagreements about the plausibility of certain theoretical claims bore on their appraisals of pursuitworthiness. It is just to claim that divergent theory choice with respect to the VMM model was often more immediately driven by researchers' divergent appraisals of problem salience and methodological approach. If your main goal was to explain Lamont's specific data, especially without invoking controversial hypotheses, then the VMM model was not at first a good bet. But if you prioritized other data or methods, it was more attractive. Focus and approach could thus easily determine theory choice.

\section{Alternative Theoretical Virtues in McClintock's Maize Genetics}

Finally, in this light, we may turn to the relation between criteria for pursuitworthiness and alternative theoretical virtues. Traditional virtues like simplicity can function as generic criteria for assessing a theory's current explanatory or epistemic value. But, as we have seen, they can also act indirectly as criteria for problem selection or methodological approach-e.g. as injunctions to simplify, rather than to 'choose' simpler theories. This helps to clarify the role of non-standard theoretical virtues, as I will now briefly argue. As a last preliminary point, though, note that alternative theoretical virtues can ground another basic explanation of divergent theory choice: rather than disagreement about shared values, as in Kuhn's model, one could also (or instead) invoke scientists' deference to different values. A final case study will illustrate this point, and especially how divergent theory choice can stem from alternative theoretical virtues functioning as non-standard criteria for research problem selection or methodological approach.

In the mid-2 $0^{\text {th }}$ century, maize geneticist Barbara McClintock theorized that chromosomal material could be rearranged in response to changes in the intracellular environment. This undermined a tacit assumption underlying the Central Dogma of molecular biology — whereby, as the biologist Francis Crick puts it, "once 'information' 
has passed into protein it cannot get out again...transfer from protein to protein, or from protein to nucleic acid is impossible" (Longino, 2002, p. 194). A model incorporating unidirectional information flow out of DNA is understandably appealing in its simplicity. But McClintock argued that this simplicity had to be sacrificed in order to generate satisfying explanations and accurate predictions of the maize pigmentation patterns that she observed. Still, it seems she herself was committed to standard explanatory desiderata insofar as she worked to develop the simplest and most general model consistent with her prior theoretical knowledge that would allow her to produce accurate predictions regarding, and explanations of, her experimental data. Nor is it the case that McClintock's detractors thought that her theoretical framework was inferior to some other account of the pigmentation patterns she isolated: there was no such alternative account. Most geneticists simply focused on different data, and correspondingly on different conceptual questions, than she did (Keller, 1983, chapters 8-11). Hence, the crucial divide between McClintock and her colleagues was not grounded in disagreement about the explanatory merits of her theory with respect to her data. Rather, this divide grew from prior disagreements about the pursuit-worthiness of her data and her methodological approach in working to explain them.

This difference in focus continued for much of McClintock's career. In the 1940s, geneticists were widely focused on heredity, with the result that investigation of the processes and mechanisms whereby cells differentiate and are organized into larger organismal structures was largely pushed aside (Keller, 1983, p. 122). In McClintock's words, "the idea of control [of the rate of genetic mutation] was not even thought of" by mainstream biologists (Keller, 1983, p. 179). By contrast, McClintock's data led her to suspect that maize possessed highly evolved systems responsible for controlling the rate of genetic mutation within the organism, and that these control mechanisms might be crucial to cellular differentiation. Moreover, whereas mainstream biologists often treated prokaryotes as paradigms of genetic structure and function, McClintock's investigation of an infrequently-studied eukaryote allowed her access to a phenomenon (genetic transposition) that was not initially observed in unicellular systems (Keller, 1983, p. 179). Her interests still overlapped with her colleagues' at abstract levels - all involved were concerned to describe genetic transfer, for instance. But these broad commonalities overlay fine-grained differences in focus that are more relevant to the concrete problem of theory choice that her work raised.

The differences in focus that isolated McClintock from the scientific mainstream are partially explicable by positing her commitment to certain non-traditional investigative norms. Specifically, she arguably valued ontological heterogeneity and complexity as loose directives for data selection and methodological approach. ${ }^{21}$ That is,

${ }^{21}$ Compare Longino $(1995,1996)$. 
McClintock's research seems to have been atypically responsive to tacit investigative heuristics in the vein of 'Pay attention to data that violate expected patterns' and 'Don't theorize difference as aberration'. She attended to differences in pigmentation of individual maize kernels, whereas she felt that "her colleagues, in their enthusiasm for 'counting,' too often overlooked that single aberrant kernel" (Keller, 1983, p. 97). McClintock thus claims that her colleagues failed to identify the patterns she noticed in part due to their tendency to abstract away difference. This is plausibly diagnosed as a mainstream commitment to simplicity as a methodological heuristic. By contrast, McClintock's own method was to "see one kernel that was different, and make that understandable" (Keller, 1983, p. 97). It was only by considering the possibility of heterogeneity in a class of objects generally assumed to be homogenous that she was able to observe such differences. And it is only because she viewed the heterogeneity she found as significant that she continued this work.

McClintock's commitment to the probative value of ontological heterogeneity is further evidenced by her skepticism of the analogy between gene regulation in unicellular and multicellular systems. Molecular biologists studying phages and bacteria often supposed that their results would apply to higher organisms, and so were skeptical about transposable genetic units in maize at least in part because they could not initially find any such genes in the unicellular systems they studied. McClintock worried that the mainstream molecular biological community tended to obscure the distinctive complexity of higher organisms as a result of this methodological faith in the representative nature of simple model organisms (Keller, 1983, p. 189). Indeed, she initially thought that genetic transposition was distinctive to multicellular systems (Keller, 1983, p. 179), perhaps because she overestimated the distance between higher and lower organisms. McClintock's exclusion from the mainstream thus seems to be rooted less in divergent conceptions of explanatory merit, per se, and more in her deference to contextually radical procedural norms. McClintock plausibly strove for good explanations, in a fairly traditional sense. But she did so with respect to problems and data not widely viewed as salient, and she deployed non-standard methodological deference to the complexity in her data.

Longino $(1995,1996)$ likewise links McClintock's work to alternative theoretical virtues like ontological heterogenity, and my analysis here is indebted to hers. ${ }^{22}$ But Longino arguably views alternative virtues like ontological heterogeneity as explanatory desiderata, not as a criteria for problem selection or methodological approach. Thus, for instance, she describes the relevant class of "cognitive or theoretical virtues" as "desirable characteristics of the outcomes of inquiry" (Longino, 1997, p. 20). By contrast to Longino's focus on the products of inquiry, I have focused on how alternative virtues

${ }^{22}$ See also Keller (1985). 
like complexity can also or instead function as criteria for choice between processes of inquiry. This contrast is important in part because it bears on the relation between alternative and traditional virtues. If alternative virtues like complexity function as domain-neutral explanatory or epistemic desiderata, then they may well stand in tension with traditional explanatory or epistemic desiderata like simplicity. But insofar as alternative virtues instead function as criteria for research problem selection or methodological approach, they are compatible with the use of traditional virtues like simplicity as criteria for evaluating success.

This last point helps to address a potential worry about my broader discussion in this section: could it not be that judgments of relative success or failure (e.g. of specific claims, if not broader theories) play a role in appraisals of problem salience or methodological approach? For instance, if I believe that the world tends to be simple, then might this not make me more optimistic about the future potential of theories that seem more amenable to simplification? ${ }^{23}$ However, note that one can accept that some parts of the world are simple( $r$ ), others (more) complex whether or not one also believes that 'The world tends to be simple' in some broader sense. In this light, researchers can evidently choose to focus on simpler or more complex phenomena, as they wish. They may do so just because they find simplicity (or complexity) to be inherently interesting, as a biologist might take organisms to be inherently interesting, if not because they embrace (or reject) Neoplatonic metaphysics. ${ }^{24}$ Or focus on complexity might advance broader political goals - e.g. Longino $(1995,1996,1997)$ argues that, in our social context, scientists' deference to virtues like simplicity perpetuates the "invisibility" of gender, whereas commitment to feminist virtues like complexity can help to "reveal" gender and gender bias. Regardless, one need not reject broad claims like "The world tends to be simple' in order to value inquiry highlighting relative complexity in nature, like 'aberrant' pigmentation patterns. To be sure, McClintock also likely had less confidence in claims like 'The position of genes on chromosomes is fixed' than did mainstream biologists. And this likely influenced her sense of her research program's pursuit-worthiness. But this is not the only kind of factor affecting pursuit-worthiness, nor obviously the most important kind. Inherent interest in certain phenomena (like complex systems) and corresponding methodological injunctions (like 'Don't oversimplify') can also play a role. And even if assessments of claims' success often play some role in appraisals of pursuit-worthiness, it can still be the latter that dictate researchers' theory choice more directly.

It would be hasty to infer from McClintock's deference to complexity in her data that she took more complex theories to be more successful. Rather, she was arguably

\footnotetext{
${ }^{23} \mathrm{I}$ am grateful to an anonymous reviewer for pressing me on this point.

${ }^{24}$ See note 11 .
} 
methodologically committed to questioning assumptions underlying certain theories' simplicity, even while maintaining a traditional explanatory preference (ceteris paribus) for simplicity - such that even she might agree that, in some sense, 'The world tends to be simple'. More broadly, alternative virtues that may seem radical if viewed as criteria for epistemic or explanatory success often have broader appeal if viewed as criteria for pursuit-worthiness.

\section{Conclusion}

Many cases in which scientists choose different research programs appear to be rooted in disagreements about which of several theories, competing to address shared questions or phenomena, is most successful-i.e. currently most epistemically or explanatorily valuable. But many such cases are in fact more directly rooted in divergent assessments of pursuit-worthiness, concerning which theory will be best down the line, or which research program addresses the most significant data or questions. I have drawn several lessons from this descriptive point:

First, some common conceptions of theory choice and attitudes like 'acceptance' have more restricted purchase on scientific practice than one might expect. This includes narrowly epistemic accounts as well as certain anti-realist accounts, like van Fraassen's or Kuhn's, that combine a theory's current and prospective value into broad notions of pragmatic acceptance or theory choice. Second, Kuhn's basic model of rational disagreement requires elaboration and refinement. Especially in cases of felt 'crisis' or stagnation, like the Copernican case that Kuhn presents in terms of present-oriented virtues like simplicity and empirical fit, divergent theory choice often centers more directly on virtues like (prospective) fruitfulness. Third, and relatedly, theoretical virtues arguably are not as widely shared as Kuhn's analysis suggests; hence, divergent theory choice can also be grounded in certain researches' deference to alternative theoretical virtues. Moreover, alternative virtues often have the broadest appeal when viewed as criteria for pursuit-worthiness.

It is fair to conclude, further, that criteria for problem salience and methodological approach are most realistically viewed as values or heuristics, rather than as precise rules dictating singular choices. In keeping with Kuhn's central claim about the desiderata for theory choice, that is, the kinds of common investigative standards that implicitly guide scientific inquiry are open to diverse interpretation, and frequently stand in tension with one another. As we have seen, these common investigative standards include commitments to collect and explain observational data with a minimum of controversial theoretical assumptions, to synthesize results from disparate subfields, to deduce testable hypotheses from controversial theoretical models, to simplify explanations, to increase predictive accuracy, to resolve inter-theoretic inconsistencies, to use simple model 
systems as an inroad to understanding complex phenomena, to pay attention to data that violate expected patterns, and to not concern oneself excessively with 'bad' or 'noisy' data. Hence, divergent theory choice results, in part, from the fact that criteria for pursuitworthiness function as values or loose heuristics.

Where scientists are not in fact choosing between theories competing to address shared questions or phenomena directly on the basis of their overall epistemic or explanatory value, it can be misguided to interrogate the justification of their behavior as if they were doing so. In particular, by failing to note how theory choice is influenced by considerations of developmental promise, problem salience, and methodological approach, one runs the risk of systematically overstating scientists' belief in the current epistemic or explanatory value of the theories that they pursue. Of course, focusing on pursuit-worthiness to the exclusion of success presents similar interpretive hazards. And, to be sure, assessments of specific claims' success often bear on appraisals of pursuitworthiness. Still, it is often the latter appraisals of pursuit-worthiness that more directly drive divergent 'theory choice'. At least with respect to issues like theoretical virtue and scientific disagreement, then, it may be productive to center analysis around structures like paradigms, research traditions, or research programs ${ }^{25}$ - which include not only scientific 'final products' like theories, claims, models, or explanations, but equally the process of inquiry.

\section{References}

Achinstein, P. (1993). How to defend a theory without testing it: Niels Bohr and the "logic of pursuit". Midwest Studies in Philosophy, 18, 90-120.

Adler, J. E. (2002). Belief's Own Ethics. Cambridge, MA: MIT Press.

Blair, A. (1990). Tycho Brahe's critique of Copernicus and the Copernican system. Journal of the History of Ideas, 51(3), 355-377.

Bonatti, E. (1973). Origin of offsets of the Mid-Atlantic Ridge in fracture zones. Journal of Geology, 81, 144-156.

Bromberger, S. (1992). On what we know and don't know: Explanation, theory, linguistics, and how questions shape them. Chicago: The University of Chicago Press.

Bueno, O. (1999). What is structural empiricism? Scientific change in an empiricist setting. Erkenntnis, 50(1), 59-85.

Carnap, R. (1950). Logical foundations of probability. Chicago: The University of Chicago Press.

Cifelli, R. (1970). Age relationships of Mid-Atlantic Ridge sediments. Geol. Soc. America Spec. Paper, 124, 47-69.

\footnotetext{
${ }^{25}$ See e.g. Kuhn (1970) on 'paradigms' and 'disciplinary matrices'; Laudan $(1977,1981)$ on 'research traditions'; and Lakatos (1978) on 'research programmes'.
} 
Cifelli, R., Blow, W. H., \& Melson, W. G. (1968). Paleogene sediments from a fracture zone of the Mid-Atlantic Ridge. Journal of Marine Research, 26, 105-109.

Cohen, L. J. (1992). An essay on belief and acceptance. New York: Clarendon Press.

Copernicus, N. (1957 [1543]). On the revolutions of the heavenly spheres (C. G. Wallis, Tras.). In R. M. Hutchins (Ed.), Great books of the western world, vol. 16: Ptolemy, Copernicus, Kepler (pp. 499-838). Chicago: The University of Chicago Press.

Dellsén, F., and Baghramian, M. (2020). Disagreement in science: introduction to the special issue. Synthese, https://doi.org/10.1007/s11229-020-02767-0.

Dorato, M. (2004). Epistemic and nonepistemic values in science. In P. Machamer, \& G. Wolters (Eds.), Science, values, and objectivity (pp. 52-77). Pittsburgh, PA: University of Pittsburgh Press.

Douglas, H. E. (2009). Science, policy, and the value-free ideal. Pittsburgh, PA: University of Pittsburgh Press.

Elgin, C. (2017). True enough. Cambridge, MA: MIT Press.

Elliott, K., \& McKaughan, D. J. (2009). How values in scientific discovery and pursuit alter theory appraisal. Philosophy of Science, 76, 598-611.

Ewing, M., Ewing, J. I., \& Talwani, M. (1964). Sediment distribution in the oceans: The MidAtlantic Ridge. Geological Society of America Bulletin, 75(1), 17-36.

Frankel, H. (1982). The development, reception, and acceptance of the Vine-Matthews-Morley Hypothesis. Historical Studies in the Physical Sciences, 13(1), 1-39.

Goldman, A. I. (1999). Knowledge in a social world. Oxford: Clarendon.

Grimm, S. R. (2008). Explanatory inquiry and the need for explanation. British Journal for the Philosophy of Science, 59(3), 481-497.

Heirtzler, J. R., \& Le Pichon. X. (1965). Crustal structure of the mid-ocean ridges: 3. Magnetic anomalies over the Mid-Atlantic Ridge. Journal of Geophysical Research 70(16), 40134033.

Hempel, C. G. (1983). Valuation and objectivity in science. In R.S. Cohen, \& L. Laudan (Eds.), Physics, philosophy, and psychoanalysis. Boston Studies in the Philosophy of Science, vol. 76 (pp. 73-100). Dordrecht: Springer

Hull, D. (1988). Science as a process. Chicago: University of Chicago Press

Keller, E. F. (1983). A feeling for the organism: The life and work of Barbara McClintock. New Haven, CT: Yale University Press.

Keller, E. F. (1985). Reflections on gender and science. San Francisco: W. H. Freeman and Company.

Kelly, T. (2013). Disagreement and the burdens of judgment. In D. Christensen, \& J. Lackey (Eds.), The Epistemology of Disagreement: New Essays (pp. 31-53). Oxford: Oxford University Press.

Kelp, C., \& Douven, I. (2012). Sustaining a rational disagreement. In H. de Regt, S. Hartmann, \& S. Okasha (Eds.), EPSA Philosophy of Science: Amsterdam 2009. The European Philosophy of Science Association Proceedings, vol 1 (pp. 101-110). Dordrecht: Springer.

Kitcher, P. (1990). The division of cognitive labor. Journal of Philosophy, 87(1), 5-22.

Koyré, A. (1943). Galileo and the scientific revolution of the seventeenth century. The Philosophical Review, 52(4), 333-348. 
Kries, J. (1886). Die principien der wahrscheinlichkeitsrechnung. Freiburg: Akademische Verlagsbuchhandlung.

Kuhn, T. S. (1957). The Copernican revolution: Planetary astronomy in the development of western thought. New York: Vintage Books.

Kuhn, T. S. (1970). The structure of scientific revolutions, $2^{\text {nd }}$ ed. New York: New American Library.

Kuhn, T. S. (1977). Objectivity, value judgment, and theory choice. In The essential tension: Selected studies in scientific tradition and change (pp. 320-339). Chicago: The University of Chicago Press.

Lackey, J. (2013). Disagreement and belief dependence: Why numbers matter. In D. Christensen, \& J. Lackey (Eds.), The Epistemology of Disagreement: New Essays (pp. 243-268). Oxford: Oxford University Press.

Lakatos, I. (1978). Philosophical Papers (J. Worrall, \& G. Currie, Eds.). Cambridge: Cambridge University Press.

Laudan, L. (1977). Progress and its problems: Towards a theory of scientific growth. Berkeley, CA: University of California Press.

Laudan, L. (1981). Science and hypothesis: Historical essays on scientific methodology. Dordrecht: Springer-Science+Business Media, B.V.

Laudan, L. (1984). Science and values. Berkeley, CA: University of California Press.

Laudan, L. (2004). The epistemic, the cognitive, and the social. In P. Machamer, \& G. Wolters (Eds.), Science, values, and objectivity (pp. 14-23). Pittsburgh, PA: University of Pittsburgh Press.

LeGrand, H. E. (1988). Drifting continents and shifting theories. Cambridge: Cambridge University Press.

Longino, H. (1990). Science as social knowledge. Princeton, NJ: Princeton University Press.

Longino, H. (1995). Gender, politics, and the theoretical virtues. Synthese, 104(3), 383-397.

Longino, H. (1996). Cognitive and non-cognitive values in science: Rethinking the dichotomy. In L. Hankinson Nelson, \& J. Nelson (Eds.), Feminism, science, and the philosophy of science (pp. 39-58). Dordrecht: Kluwer Academic Publishers.

Longino, H. (1997). Feminist epistemology as a local epistemology. Proceedings of the Aristotelian Society, Supplementary Volumes, 71, 19-35.

Longino, H. (2002). The fate of knowledge. Princeton, NJ: Princeton University Press.

McMullin, E. (1976). The fertility of theory and the unit for appraisal in science. In R. S. Cohen, P. K. Feyerabend, \& M. Wartofsky (Eds.), Essays in Memory of Imre Lakatos (pp. 393432). Dordrecht: D. Reidel.

McMullin, E. (1982). Values in science. PSA: Proceedings of the Biennial Meeting of the Philosophy of Science Association, 2, 3-28.

McMullin, E. (1993). Rationality and paradigm change in science. In P. Horwich (Ed.), World changes: Thomas Kuhn and the nature of science (pp. 55-78). Cambridge, MA: MIT Press.

Melson, W. G., Hart, S. R., \& Thompson, G. (1972). St. Paul Rocks, equatorial Atlantic: petrogenesis, radiometric ages and implication on sea floor spreading. Geol. Soc. Am. Mem., 132, 241-272.

Nagel, E. (1939). Principles of the theory of probability. Chicago: The University of Chicago Press. 
Naylor, R. (2003). Galileo, Copernicanism, and the origins of the new science of motion. British Journal for the History of Science, 36(2), 151-181.

Nyrup, R. (2015). How explanatory reasoning justifies pursuit: A Peircean view of IBE. Philosophy of Science, 82, 749-760.

Nyrup, R. (2019). "Of water drops and atomic nuclei": Analogies and pursuit worthiness in science. British Journal for the Philosophy of Science, 71(3), 881-903.

Quine, W. V. O., \& Ulian, J. S. (1970). The web of belief. New York: Random House.

Rowbottom, D. P. (2010). What scientific progress is not: Against Bird's epistemic view. International Studies in the Philosophy of Science, 24(3), 241-255.

Rowbottom, D. P. (2018). What is (dis)agreement? Philosophy and Phenomenological Research, 97(1), 223-236.

Rowbottom, D. P. (2019). The instrument of science: Scientific anti-realism revitalised. London: Routledge.

Saito, T., Ewing, M., \& Burckle, L. H. (1966). Tertiary sediment from the mid-atlantic ridge. Science, 151, 1075-1079.

Schindler, S. (2018). Theoretical virtues in science: Uncovering reality through theory. Cambridge: Cambridge University Press.

Seidel, M. (2019). Kuhn's two accounts of rational disagreement in science: an interpretation and critique. Synthese, https://doi.org/10.1007/s11229-019-02113-z.

Šešelja, D., \& Straßer, D. (2013). Kuhn and the question of pursuit worthiness. Topoi, 32, 9-19.

van Fraassen, B. (1980). The scientific image. Oxford: Oxford University Press.

van Fraassen, B. (2007). From a view of science to a new empiricism. In B. Monton (Ed.), Images of Empiricism: Essays on Science and Stances, with a Reply from Bas C. van Fraassen (pp. 337-383). Oxford: Oxford University Press.

Vine, F. J., \& Matthews, D. H. (1963). Magnetic anomalies over oceanic ridges. Nature, 199, 947-949.

Weinberger, N., \& Bradley, S. (2020). Making sense of non-factual disagreement in science. Studies in History and Philosophy of Science Part A, 83, 36-43.

Westman, R. S. (1975). The Melancthon circle, Rheticus, and the Wittenberg interpretation of the Copernican theory. Isis, 66(2), 164-193.

Westman, R. S. (1994). Two cultures or one? A second look at Kuhn's The Copernican Revolution. Isis, 85(1), 79-115.

Whitt, L. A. (1990). Theory pursuit: Between discovery and acceptance. PSA: Proceedings of the Biennial Meeting of the Philosophy of Science Association, 1, 467-483. 